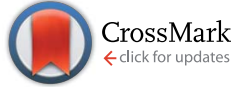

Cite this: J. Mater. Chem. A, 2015, 3, 1986

Received 24th October 2014 Accepted 25th November 2014

DOI: $10.1039 / c 4 t a 05703 a$

www.rsc.org/MaterialsA

\section{Diselenogermole as a novel donor monomer for low band gap polymers $\uparrow$}

\author{
Zhuping Fei, ${ }^{a}$ Raja Shahid Ashraf, ${ }^{a}$ Yang Han, ${ }^{\text {ac }}$ Sarah Wang, ${ }^{\text {b }}$ Chin Pang Yau, ${ }^{a}$ \\ Pabitra S. Tuladhar, ${ }^{a}$ Thomas D. Anthopoulos, ${ }^{c}$ Michael L. Chabinyc ${ }^{b}$ \\ and Martin Heeney ${ }^{\star a}$
}

We report the synthesis of a new diseleno[3,2-b:2', $\left.3^{\prime}-d\right]$ germole (DSG) monomer containing branched 2ethylhexyl sidechains on the bridging germanium group. The utility of this new electron rich monomer is explored by co-polymerisation of a distannylated DSG monomer with $\mathrm{N}$-octylthienopyrrolodione to afford a soluble low band gap polymer. The DSG containing polymer shows a broader and more redshifted absorption spectrum compared its thiophene analogue. Polymer solar cells are fabricated from blends with $\mathrm{PC}_{71} \mathrm{BM}$ exhibiting initial power conversion efficiencies of $5.2 \%$ in inverted bulk heterojunction solar cells.

\section{Introduction}

There has been significant interest in the development of fused aromatic units for incorporation into conjugated polymer backbones. ${ }^{1}$ In particular the development of building blocks in which aromatic units such as benzene or thiophene are rigidly held in a co-planar arrangement by the use of bridging heteroatoms has been a successful approach to the development of polymers for field effect transistor (FET) or photovoltaic (OPV) applications. ${ }^{2}$ The use of fully co-planar building blocks prevents any torsional twisting between the adjacent aromatic units, which potentially leads to a reduction in conjugation length and an increase in reorganizational energy. More rigid co-monomers can also enhance polymer persistence length, which has been correlated with better transport. ${ }^{3}$ In addition, the bridging atom fulfils an important role as the point of attachment for solubilising alkyl sidechains and as a defining factor in the geometry of the backbone by modifying the bond angles in the monomer. ${ }^{4}$

Many of the best performing classes of these ladder-like monomers contain thiophene as the aromatic unit, and a variety of bridging heteroatoms. For example bridged 2,2'bithiophenes have been well investigated, with polymers of cyclopentadithiophene ${ }^{2 d}$ (which contain a C bridge) exhibiting very promising $\mathrm{FET}^{5}$ and $\mathrm{OPV}^{6}$ performance. The ability of the polymers to crystallise, as well as the ionisation and reduction

${ }^{a}$ Department of Chemistry and Centre for Plastic Electronics, Imperial College London, London, SW7 2AZ, UK. E-mail: m.heeney@imperial.ac.uk

${ }^{b}$ Materials Department, University of California, Santa Barbara, CA 93106-5050, USA 'Department Physics and Centre for Plastic Electronics, Imperial College London, SW7 $2 A Z, U K$

$\dagger$ Electronic supplementary information (ESI) available. See DOI: 10.1039/c4ta05703a potentials can be influenced by changing the bridging heteroatom. ${ }^{7}$ For example, changing from $\mathrm{C}$ to Si (dithienosilole, DTS) or Ge (dithienogermole, DTG) whilst maintaining identical sidechains has been shown to enhance polymer crystallinity and solar cell performance, whilst simultaneously lowering both the HOMO and LUMO energy levels. ${ }^{8}$ The increased crystallinity has been rationalised by the longer $\mathrm{C}-\mathrm{Si} / \mathrm{C}-\mathrm{Ge}$ bond compared to the $\mathrm{C}-\mathrm{C}$ bond, which alters the geometry of the monomer building block, enhancing intramolecular interactions. ${ }^{8}$ These interesting observations have resulted in the copolymerisation of DTS and DTG with a wide range of monomers in an effort to further fine tune to polymer optoelectronic properties and solid state organisation. ${ }^{9}$

Another approach to control the properties of semiconducting polymers has been to change the nature of the heterocycle, for example changing from thiophene to selenophene. The replacement of $\mathrm{S}$ for Se, which is larger and more polarisable has been proposed to improve intermolecular contacts in polymer thin films,${ }^{10}$ resulting in improved charge carrier mobility in some cases. The reduced aromaticity of selenophene in comparison to thiophene also improves delocalisation of the conjugated system into the polymer backbone, often resulting in reduction in the optical band gap. ${ }^{11}$ These desirable properties have prompted much interest in selenophene containing polymers for both solar cell and transistor applications. ${ }^{12}$ Despite this interest, to the best of our knowledge there have been no reports of the incorporation of bridged diselenophene monomers into conjugated polymers. There has been notable work on the development of diselenopheno[3,2-b:2,3- $d]$ pyrrole $^{13}$ ( $\mathrm{N}$ bridge) as well as cyclopenta[2,1-b:3,4- $\left.b^{\prime}\right]$ diselenophene-4-one ${ }^{14}((\mathrm{C}=\mathrm{O})$ bridge $)$ by Marder and co-workers, but so far their properties have only been reported as monomeric materials. 
Here we report the first synthesis of diseleno[3,2- $\left.b: 2^{\prime}, 3^{\prime}-d\right]$ germole, (DSG), the selenophene analogue to DTG, and its copolymerisation with $\mathrm{N}$-octylthienopyrrolodione (TPD) to afford a new low band gap polymer (PDSGTPD). Recently we, and others, have been interested in the potential of DTG based donor-acceptor materials, ${ }^{\mathbf{9}-\boldsymbol{d} \boldsymbol{d}, \mathbf{9 g}-\boldsymbol{j}, \mathbf{1 5}}$ because the incorporation of the bridging dialkylgermanium improves the chemical stability of the monomer in comparison to the silicon bridged material leading to greater tolerance of synthetic conditions. ${ }^{9 b}$ We have further developed this stable unit by synthesizing the selenophene analogue and using it as a co-monomer in a model donor-acceptor polymer. TPD was chosen as a suitable comonomer because of the presence of the additional solubilising octyl group, which was expected to counter the reduction in solubility often encountered upon the inclusion of the heavier Se heteroatom. The reduction in solubility is related to the enhanced quinoidal character of selenophene containing polymers, ${ }^{\mathbf{1 1}, 16}$ which planarises the polymer backbone, as well as the reduction in the percentage of solubilising alkyl content due to the heavier mass of Se. TPD also has a relatively strong electron withdrawing effect due to the presence of the imide group and this was expected to lead to polymers with relatively high ionisation potentials, which are desirable in both OPV and FET applications. ${ }^{17}$ We report the optoelectronic properties of this new polymer, and compare them to the previously reported thiophene analogue, as well as report the properties of the polymer in FET and OPV devices.

\section{Experimental section}

\section{General}

Reagents and chemicals were purchased from Aldrich and Acros unless otherwise noted. 3,3'-Dibromo-5, $5^{\prime}$-bis(trimethylsilyl)-2,2'-biselenophene ${ }^{\mathbf{1 3 b}}$ (1) dibromo-di-(2-ethylhexyl) germane ${ }^{9 b}$ and 1,3-dibromo-5-octyl-4H-thieno[3,4-c]pyrrole-4,6(5H)-dione ${ }^{\mathbf{1 7 a , 1 8}}$ were synthesized by the reported method. The thiophene polymer PDTGTPD was identical to that reported in ref. 21 .

All reactions were carried out under Ar using solvents and reagents as commercially supplied, unless otherwise stated. ${ }^{1} \mathrm{H}$ and ${ }^{13} \mathrm{C}$ NMR spectra were recorded on a Bruker AV-400 (400 $\mathrm{MHz}$ ), using the residual solvent resonance of $\mathrm{CDCl}_{3}$ or $d$-1,1,2,2-tetrachloroethane and are given in ppm. Numberaverage $\left(M_{\mathrm{n}}\right)$ and weight-average $\left(M_{\mathrm{w}}\right)$ were determined by Agilent Technologies 1200 series GPC running in chlorobenzene at $80{ }^{\circ} \mathrm{C}$, using two PL mixed B columns in series, and calibrated against narrow polydispersity polystyrene standards. Electrospray mass spectrometry was performed with a Thermo Electron Corporation DSQII mass spectrometer. UV-vis spectra were recorded on a UV-1601 Shimadzu UV-vis spectrometer. Flash chromatography was performed on silica gel (Merck Kieselgel 60 F254 230-400 mesh). Photo Electron Spectroscopy in Air (PESA) measurements were recorded with a Riken Keiki AC-2 PESA spectrometer with a power setting of $5 \mathrm{nW}$ and a power number of 0.5. Samples for PESA were prepared on glass substrates by spin-coating. Differential Scanning Calorimetry (DSC) measurements: $\sim 4 \mathrm{mg}$ material was used for the DSC experiments, which was conducted under nitrogen at scan rate of $10{ }^{\circ} \mathrm{C} \mathrm{min}^{-1}$ with a TA DSC Q20 instrument. Cyclic voltammetry (CV) were carried out with standard three-electrode cell in a $0.1 \mathrm{M}$ tetrabutylammonium hexafluorophosphate $\left(\mathrm{TBAPF}_{6}\right)$ solution in acetonitrile at room temperature with a scanning rate of $0.05 \mathrm{~V} \mathrm{~s}^{-1}$. A Pt wire counter electrode, a glass carbon working electrode, and an $\mathrm{Ag} / \mathrm{AgCl}$ reference electrode were used. The oxidation potentials were calibrated with a standard ferrocene/ferrocenium (FOC) redox system as the internal standard (assuming the energy level of FOC is $4.8 \mathrm{eV}$ below vacuum) for estimating the HOMO energy level of polymers. The polymer film was drop cast onto the working electrode from a $5 \mathrm{mg} \mathrm{mL} \mathrm{m}^{-1}$ chlorobenzene solution, and dried at room temperature.

\section{OFET (organic field effect transistors) devices fabrication}

Bottom gate/top contact devices were fabricated on heavily doped $\mathrm{n}^{+}$-Si (100) wafers with a $400 \mathrm{~nm}$-thick thermally grown $\mathrm{SiO}_{2}$ gate dielectric. The $\mathrm{Si} / \mathrm{SiO}_{2}$ substrates were treated with OTS to form a self-assembled monolayer before deposition of the polymer. PDSGTPD was dissolved in dichlorobenzene $(5 \mathrm{mg}$ $\mathrm{mL}^{-1}$ ) and spin cast at $2000 \mathrm{rpm}$ for $60 \mathrm{~s}$ in nitrogen atmosphere. No annealing procedure was carried out. Au (30 nm) source and drain electrodes were deposited under vacuum through shadow masks. The channel width and length of the transistors are $1000 \mu \mathrm{m}$ and $30 \mu \mathrm{m}$, respectively. Mobility was extracted from the slope of $I_{\mathrm{D}}^{1 / 2} v s$. $V_{\mathrm{G}}$.

\section{OPV fabrication and characterization}

Organic photovoltaic devices were fabricated using PDSGTPD and [6,6]-phenyl $\mathrm{C}_{71}$ butyric acid methyl ester $\left(\mathrm{PC}_{71} \mathrm{BM}\right.$, purchased from Nano $\mathrm{C}$ Inc.) as the donor and acceptor materials. Devices were fabricated onto the indium tin oxide (ITO) coated substrates with the device structures of ITO/PEDOT:PSS/ PDSGTPD:PC ${ }_{71} \mathrm{BM} / \mathrm{LiF} / \mathrm{Al}$ and ITO/ZnO/PDSGTPD:PC ${ }_{71} \mathrm{BM} /$ $\mathrm{MoO}_{3} / \mathrm{Ag}$. For the conventional ITO/PEDOT:PSS/ PDSGTPD: $\mathrm{PC}_{71} \mathrm{BM} / \mathrm{LiF} / \mathrm{Al}$ device, after sequential cleaning of the ITO with the detergent (Mucasol), acetone and isopropyl alcohol, a $30 \mathrm{~nm}$ layer of PEDOT:PSS (AI4083) was spin-coated onto the plasma-treated ITO substrate and annealed at $150{ }^{\circ} \mathrm{C}$ for $30 \mathrm{~min}$. For inverted ITO/ZnO/PDSGTPD: $\mathrm{PC}_{71} \mathrm{BM} / \mathrm{MoO}_{3} / \mathrm{Ag}$, after sequential cleaning of the ITO with the detergent (Mucasol), acetone and isopropyl alcohol, $\mathrm{ZnO}$ was deposited by spincoating a zinc acetate dihydrate precursor solution $(2 \mathrm{~mL} 2$ methoxyethanol with $60 \mu \mathrm{L}$ monoethanolamine) followed by annealing at $150{ }^{\circ} \mathrm{C}$ for $10-15 \mathrm{~min}$. PDSGTPD: $\mathrm{PC}_{71} \mathrm{BM}$ solution in dichlorobenzene (ODCB) at a ratio of $1: 1$ to $1: 4$ were stirred overnight at $80{ }^{\circ} \mathrm{C}$. 1,8-diiodooctane (DIO, $3 \% \mathrm{v} / \mathrm{v}$ ) was used as an additive and added prior to spin coating. The blend solution (12 $\mathrm{mg} \mathrm{mL} \mathrm{m}^{-1}$ for PDSGTPD) was spin coated onto the PEDOT:PSS or ZnO coated ITO substrate (2000 rpm, $1 \mathrm{~min}$ ). For the power conversion efficiency (PCE) measurement of OPV devices, we used the thermally deposited $\mathrm{LiF}(1 \mathrm{~nm}) / \mathrm{Al}(100 \mathrm{~nm})$ or $\mathrm{MoO}_{3}(10 \mathrm{~nm}) / \mathrm{Ag}(100 \mathrm{~nm})$ cathode. Electrical characteristics were measured by Keithley 236 source/measure units under AM 1.5 solar illumination (Oriel $300 \mathrm{~W}$ solar simulator) at an 
intensity of $100 \mathrm{~mW} \mathrm{~cm}$ with a device area of $0.045 \mathrm{~cm}^{2}$. All electrical measurements of OPVs were executed in the inert nitrogen purged devices chamber.

\section{Synthesis of monomer and polymer}

4,4'-Bis(2-ethyl-hexyl)-5,5'-dibromo-diseleno[3,2-b:2', $\left.3^{\prime}-d\right]$ germole (2). A solution of $n$-BuLi $(7.6 \mathrm{~mL}$ of a $1.6 \mathrm{M}$ solution in hexanes, $12.2 \mathrm{mmol}$ ) was added dropwise to a solution of $3,3^{\prime}$ dibromo-5,5'-bis(trimethylsilyl)-2,2'-biselenophene (3.26 g, 5.8 $\mathrm{mmol})$ in THF $(150 \mathrm{~mL})$ at $-100{ }^{\circ} \mathrm{C}$. After stirring for $20 \mathrm{~min}$ at this temperature, dibromo-di-(2-ethylhexyl)germane ( $2.93 \mathrm{~g}, 6.4$ $\mathrm{mmol})$ in THF $(10 \mathrm{~mL})$ was added dropwise. The cooling bath was removed and the reactant was allowed to warm to RT, followed by stirring for $0.5 \mathrm{~h}$ at RT. Water $(30 \mathrm{~mL})$ was added, and the mixture extracted $(3 \times 30 \mathrm{~mL}$ hexane $)$. The combined organics were dried $\left(\mathrm{MgSO}_{4}\right)$, filtered and concentrated under reduced pressure. The residue was purified by silica gel chromatography (eluent: hexane) to afford a pale yellow oil (2.2 g).

To the resulting oil in THF $(100 \mathrm{~mL})$ was added $N$-bromosuccinimide (NBS) $(1.42 \mathrm{~g}, 8.0 \mathrm{mmol})$ in one portion at $0{ }^{\circ} \mathrm{C}$ and the mixture was stirred for $1 \mathrm{~h}$ in the absence of light. An aqueous saturated solution of $\mathrm{Na}_{2} \mathrm{SO}_{3}(50 \mathrm{~mL})$ was added to quench the reaction. The mixture was extracted with hexane (3 $\times 50 \mathrm{~mL})$. The combined organics were dried $\left(\mathrm{MgSO}_{4}\right)$, filtered and the solvent removed solvent under reduced pressure. The residue was purified by silica gel chromatography (eluent: hexane) to afford 2 as a pale yellow oil $(2.14 \mathrm{~g}$, yield: $52 \%) .{ }^{1} \mathrm{H}$ NMR ( $\left.\mathrm{CDCl}_{3}, 400 \mathrm{MHz}\right), \delta(\mathrm{ppm}): 7.14(\mathrm{~s}, 2 \mathrm{H}), 1.47-1.41(\mathrm{~m}, 2 \mathrm{H})$, 1.27-1.12 (m, 20H), 0.87-0.77 (m, 12H). ${ }^{13} \mathrm{C}$ NMR $\left(\mathrm{CDCl}_{3}, 100\right.$ $\mathrm{MHz}), \delta$ (ppm): 160.6, 152.6, 144.3, 135.1, 114.9, 36.9, 35.4, 28.9, 28.8, 23.0, 20.9, 14.1, 10.9. HRMS (EI)+ calculated for $\mathrm{C}_{24} \mathrm{H}_{36}-$ $\mathrm{Br}_{2} \mathrm{GeSe}_{2}$ : 715.8726. Found: 715.8743 .

4,4'-Bis(2-ethyl-hexyl)-2,6-bis(trimethyltin)-dithieno[3,2$\left.\boldsymbol{b}: \mathbf{2}^{\prime}, \boldsymbol{3}^{\prime}-\boldsymbol{d}\right]$ germole (3). A solution of $n$-BuLi $(2.3 \mathrm{~mL}$ of a $1.6 \mathrm{M}$ solution in hexanes, $3.7 \mathrm{mmol}$ ) was added dropwise to a solution of $4,4^{\prime}$-bis(2-ethyl-hexyl)-diseleno[3,2-b:2 $2^{\prime}, 3^{\prime}$-d]germole (2) $(1.10 \mathrm{~g}, 1.54 \mathrm{mmol})$ in THF $(100 \mathrm{~mL})$ at $-100{ }^{\circ} \mathrm{C}$. After stirring for $20 \mathrm{~min}$ at this temperature, trimethyltin chloride $(4.6 \mathrm{~mL}$ of a $1 \mathrm{M}$ solution in THF, $4.6 \mathrm{mmol}$ ) was added dropwise. The cooling bath was removed and the reactant was allowed to warm to RT, followed by stirring for $0.5 \mathrm{~h}$ at RT. Water $(50 \mathrm{~mL})$ was added, and the mixture extracted $(3 \times 50 \mathrm{~mL}$ hexane $)$. The combined organics were dried $\left(\mathrm{MgSO}_{4}\right)$, filtered and concentrated under reduced pressure. The residue was purified by preparative GPC in hexane to afford a pale yellow oil $(1.14 \mathrm{~g}$, yield: $84 \%) .{ }^{1} \mathrm{H} \mathrm{NMR}\left(\mathrm{CDCl}_{3}, 400 \mathrm{MHz}\right), \delta(\mathrm{ppm}): 7.33(\mathrm{~s}, 2 \mathrm{H})$, 1.53-1.45 (m, 2H), 1.32-1.16 (m, 20H), 0.88-0.77 (m, 12H), 0.36 (s, $18 \mathrm{H}) .{ }^{13} \mathrm{C}$ NMR $\left(\mathrm{CDCl}_{3}, 100 \mathrm{MHz}\right), \delta$ (ppm): 158.0, 146.5, 145.7, 140.2, 37.0, 35.5, 28.9, 28.8, 23.1, 20.8, 14.2, 10.9, -7.8. TOF MS (ES)+: calculated for $\mathrm{C}_{30} \mathrm{H}_{54} \mathrm{GeSe}_{2} \mathrm{Sn}_{2}:$ 883.9942. Found: 883.9937.

Poly $\left\{5,5^{\prime}\left(4,4^{\prime}\right.\right.$-bis-(2-ethylhexyl)-diseleno[3,2-b:2', $3^{\prime}$-d] germole)alt-1,3(5-octyl-4H-thieno[3,4-c]pyrrole-4,6(5H)-dione\} (PDSGTPD). To an oven-dried $2 \mathrm{~mL}$ high pressure microwave reactor tube equipped with a sealed septum was added the following reagents in a sequential fashion: compound (3) (453 mg, $0.51 \mathrm{mmol})$,
1,3-dibromo-5-octyl-4H-thieno[3,4-c]pyrrole-4,6(5H)-dione (217 mg, $0.51 \mathrm{mmol}), \mathrm{Pd}_{2}(\mathrm{dba})_{3}(9.4 \mathrm{mg}, 0.01 \mathrm{mmol})$ and $\mathrm{P}-(o \text {-tol })_{3}(12.5 \mathrm{mg}$, $0.04 \mathrm{mmol}$ ). The tube was sealed and flushed with Ar, and chlorobenzene $(1.5 \mathrm{~mL})$ was added. The solution was thoroughly degassed under Ar, and then the argon inlet was removed. The tube was subjected to the following conditions in a microwave reactor: $120^{\circ} \mathrm{C}$ for $2 \mathrm{~min}, 140{ }^{\circ} \mathrm{C}$ for $2 \mathrm{~min}$ and $180^{\circ} \mathrm{C}$ for $30 \mathrm{~min}$. After cooling to RT, the polymer was precipitated into methanol $(100 \mathrm{~mL})$, and filtered through a Soxhlet thimble. The polymer was extracted using Soxhlet apparatus with methanol, acetone, hexane, and chloroform. The chloroform solution was concentrated and precipitated into methanol, and the precipitant was filtered and dried under vacuum to afford a dark solid (252 $\mathrm{mg}$, yield: $60 \%$ ). The polymer was purified by preparative GPC column (eluent: chlorobenzene) and PDSGTPD was obtained (101 mg, yield: 24\%, $\left.M_{\mathrm{n}}=41 \mathrm{~K}, \mathrm{PDI}=1.5\right) .{ }^{1} \mathrm{H}$ NMR $(d-1,1,2,2$-tetrachloroethane, 400 $\mathrm{MHz}, 130^{\circ} \mathrm{C}$ ), $\delta(\mathrm{ppm}): 8.00$ (s, broad, $\left.2 \mathrm{H}\right), 3.76(\mathrm{t}$, broad, $2 \mathrm{H}), 1.83-$ 1.34 (m, broad, $34 \mathrm{H}), 1.03-0.92(\mathrm{~m}$, broad, $15 \mathrm{H})$. UV-vis (chlorobenzene, $\left.10^{-5} \mathrm{M}\right) \lambda_{\max }(\log \varepsilon) 661(4.66), 722(4.76) \mathrm{nm}$. Anal. calcd: $\left(\mathrm{C}_{38} \mathrm{H}_{53} \mathrm{GeNO}_{2} \mathrm{SSe}_{2}\right)_{n}: \mathrm{C}, 55.76 ; \mathrm{H}, 6.53 ; \mathrm{N}, 1.71$. Found: C, 55.89; H, $6.50 ; \mathrm{N}, 1.60$.

\section{Results and discussion}

The synthesis of diselenogermole (DSG), and its subsequent polymerisation to afford PDSGTPD is shown in Scheme 1. To enhance the polymer solubility, branched 2-ethylhexyl side chains were employed as the bridging groups. The starting material 3,3'-dibromo-5,5'-bis(trimethylsilyl)-2, $2^{\prime}$-biselenophene 1 was prepared as reported by the base catalysed rearrangement and subsequent oxidative coupling of 5-bromo2-trimethylsilylselenophene. ${ }^{13 b}$ Our initial attempts to synthesise DSG repeated the conditions used to prepare the DTG, namely the treatment of $\mathbf{1}$ with 2.2 equivalents of $n$-BuLi in THF at $-78{ }^{\circ} \mathrm{C}$, followed by the addition of the dibromo-di(2-ethylhexyl)germane. However only very low yields of DSG were isolated under these conditions, with the majority of the mass balance being decomposition products, presumably formed by the ring opening of the lithiated selenophene. ${ }^{19}$ Cooling the reaction to $-100{ }^{\circ} \mathrm{C}$ improved the stability of the 3lithiated selenophene, and the reaction proceeded smoothly under these conditions. Purification of the crude product was complicated by the proto-desilylation of the trimethylsilyl groups during column chromatography over silica. Therefore, the crude mixture of partially desilylated diselenogermoles resulting from the reaction was brominated directly with excess NBS. The intermediate dibromodiselenogermole (2) could be readily purified by column chromatography, and was isolated in a yield of $52 \%$ from 1 .

The dibromodiselenogermole (2) was stannylated by treatment with 2.4 equivalents of $n$-BuLi again at $-100{ }^{\circ} \mathrm{C}$, followed by the addition of trimethyltin chloride. Similar to the thiophene analogue, the crude product destannylated on normal phase silica, so we purified by preparative gel permeation chromatography on cross-linked polystyrene to afford the final monomer 3 in a yield of $84 \%$. Polymerisation of 3 and 1,3dibromo-5-octyl-4H-thieno[3,4-c]pyrrole-4,6(5H)-dione was 

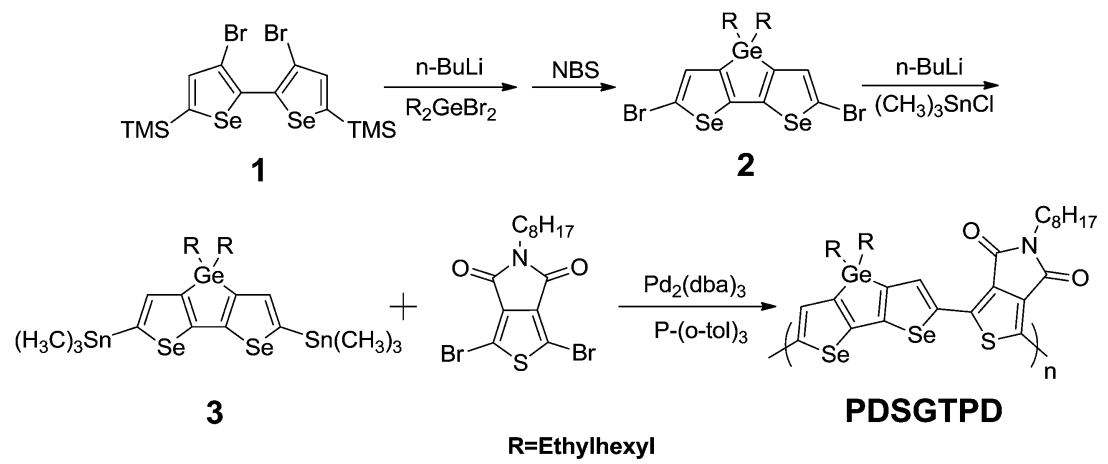

Scheme 1 Synthetic route to PDSGTPD.

performed by Stille coupling under microwave-assisted condition. ${ }^{20}$ After precipitation and solvent extraction to remove lower weight oligomers and catalyst residues, the polymer was purified by preparative GPC (chlorobenzene) and reprecipitation. The resulting polymer exhibited reasonable solubility in chlorinated solvents like chlorobenzene upon gentle warming. PDSGTPD had a number average molecular weight $\left(M_{\mathrm{n}}\right)$ of 41 KDa with a PDI of 1.5 as determined by GPC against polystyrene standards. Differential scanning calorimetry (DSC) (Fig. S1†) showed no obvious thermal transitions for the polymer upon cycling between 0 and $300{ }^{\circ} \mathrm{C}$.

The UV-vis absorption spectra of PDSGTPD in dilute chlorobenzene (CB) and as a spun-cast thin film are shown in Fig. 1. The polymer exhibits an absorption maximum at $722 \mathrm{~nm}$ with a pronounced shoulder at $661 \mathrm{~nm}$ in solution, and the thin film exhibits a very similar spectral shape, with a modest red shift in $\lambda_{\max }$ to $728 \mathrm{~nm}$, with the shoulder at $662 \mathrm{~nm}$. The separation of peaks of approximately $0.15 \mathrm{eV}$ is consistent with a vibronic progression, as observed in many ordered semiconducting polymers. The similarity between the solution and thin film spectra suggest polymer aggregation in solution. The UV spectra of the analogous thiophene polymer PDTGTPD ${ }^{9 a, 21}$ are included for comparison in Fig. 1. It can be seen that PDSGTPD exhibits a near identical spectral shape but both absorption peaks are redshifted by approximately $50 \mathrm{~nm}$. The extinction coefficient of

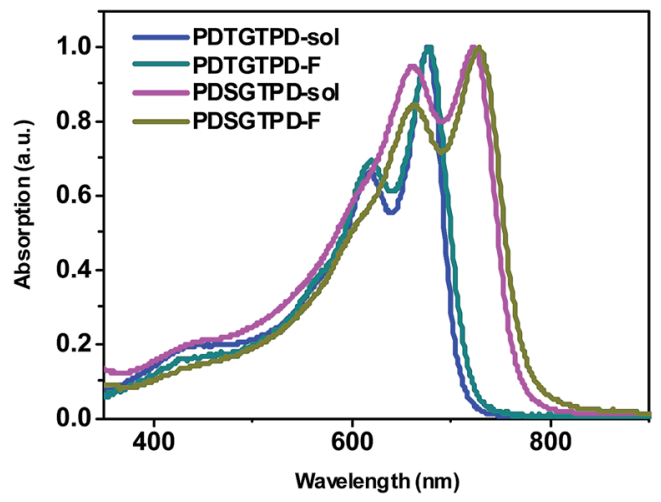

Fig. 1 UV-vis spectra of PDTGTPD and PDSGTPD in dilute chlorobenzene and as spun cast thin films. the polymer in solution ( $\varepsilon 58000 \mathrm{~cm}^{-1}$ at $\lambda_{\max }$ ) is approximately equal to that reported for the thiophene analogue ( $\varepsilon 51900$ $\mathrm{cm}^{-1}$ at $\lambda_{\max }$ ) of similar molecular weight in chlorobenzene under equivalent dilution. ${ }^{21}$ The absorption onset of PDSGTPD in the solid state is $775 \mathrm{~nm}$, corresponding to an optical band gap of $1.60 \mathrm{eV}$. This is $0.1 \mathrm{eV}$ less than the optical band gap of the thiophene analogue. The red shift in the absorption peaks and reduction in optical band gap, are consistent with previous experimental and theoretical studies on selenophene substitution. ${ }^{10-12}$

The ionization potential of a thin film of this polymer was measured by photo electron spectroscopy in air (PESA) to be $5.12( \pm 0.05) \mathrm{eV}$. This is equivalent, within experimental error, to the value measured by the same technique for films of the thiophene analogue (I.P. $=5.1 \pm 0.05 \mathrm{eV}$ ) ${ }^{21}$ This suggests that the most significant effect of replacing thiophene for selenophene is to stabilize the polymer LUMO, leading to the observed reduction in band gap. This observation is further supported by cyclic voltammetry (CV) measurements of the films on glassy carbon electrodes in anhydrous, degassed solutions of acetonitrile with tetrabutylammonium hexafluorophosphate $(0.1 \mathrm{M})$ electrolyte. The cyclic voltammogram of the polymer is shown in Fig. $\mathrm{S} 2 \dagger$ (potentials were measured against an $\mathrm{Ag} / \mathrm{Ag}+$ reference electrode). The HOMO and LUMO levels were estimated to -5.29 and $-3.40 \mathrm{eV}$, respectively (by the onset of the first oxidation and reduction potential, assuming the ferrocene/ ferrocenium reference redox system is $4.8 \mathrm{eV}$ below the vacuum level). This compares to values of 5.28 and $3.18 \mathrm{eV}$ measured for the analogous thiophene polymer by $\mathrm{CV}^{9 a}$

In order to further probe the influence of the heteroatom on the polymer structure and energy levels, quantum mechanical calculations at the B3LYP/6-31G* level of theory were performed on model trimers using Gaussian 09. The side chains were modified to methyl groups in order to simplify the calculations. Frequency calculations were performed on the lowest energy conformations to ensure the geometry was not the result of a local minimum. For comparative purposes, the thiophene analogue DTGTPD was also calculated, and the structure is shown in the ESI. $\dagger$ The minimum energy conformation of the DSGTPD trimer (Fig. 2a) reveals the planar structure of this molecule. The thiophene analogue is similarly fully coplanar (Fig. S3†) The HOMO and LUMO of DSGTPD are predicted to be 
(a)

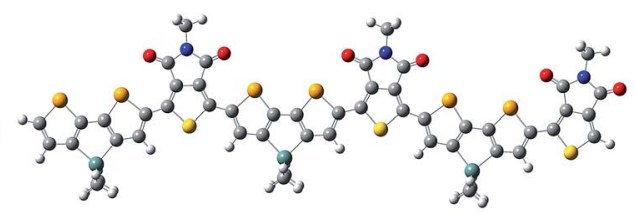

(b)

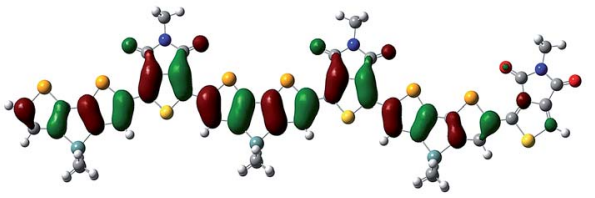

(c)

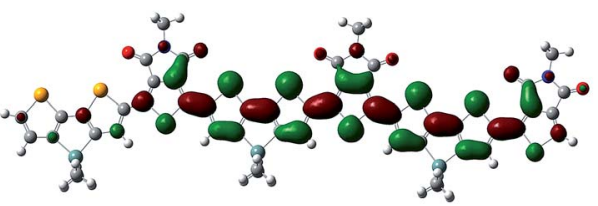

Fig. 2 Energy-minimized conformation (B3LYP/6-31G*) (a), HOMO (b) and LUMO (c) distributions of a methyl substituted DSGTPD trimer.

delocalized over the entire conjugated backbones (Fig. 2b and c), although due to the asymmetry of the oligomer, a clear edge effect is observed with the HOMO localizing towards the electron rich DSG end and the LUMO towards the electron deficient TPD end. The HOMO is predominantly aromatic and the LUMO has quinoidal character. Comparing the selenophene to the thiophene polymer, the HOMO is predicted to rise in energy slightly ( $-4.87 \mathrm{eV}$ for DSG versus $-4.91 \mathrm{eV}$ for DTG) upon selenophene inclusion, and the LUMO lower $(-3.03 \mathrm{eV}$ for DSG versus $-2.98 \mathrm{eV}$ for DTG), resulting in a net reduction of band gap of $0.09 \mathrm{eV}$, which is close to the shift in the optical gap observed experimentally. The small difference in HOMO levels is within the experimental error of our PESA experiments, although as discussed later, the selenophene polymer does have a slightly lower open circuit voltage in solar cells, consistent with a slightly higher lying HOMO level.

Interestingly the DFT calculations also predict subtle differences in the molecular geometries of the two polymers. For comparative purposes we base our discussions here on the central DSG or DTG unit of the modeled trimers, since this is most representative of a section of the polymer chain and minimizes the edge effects mentioned above. As expected the inclusion of the larger Se atom, leads to a lengthening of the
$\mathrm{C}-\mathrm{X}$ (S or Se) bond in the fused unit, from $1.77 \AA$ in DTG to $1.90 \AA$ in DSG. The longer C-Se bond also has the effective of making the DSG unit more linear in comparison to DTG, thus the angle between the $5,5^{\prime}$ positions is approximately $28^{\circ}$ for DSG and $36^{\circ}$ for DTG (see Fig. S4 $\dagger$ ). The lengthening of C-Se bond is also predicted to place the Se in slightly closer proximity (2.94 Å) to the oxygen of the carbonyl of the TPD, than for DTG $(2.99 \AA)$ despite the larger size of Se. In both cases the predicted interaction is less than the sum of the van der Waal's radii, and although we note caution should be applied to the interpretation of DFT results, they do suggest that the inclusion of the Se does not cause significant disruption to the planarity of the backbone.

The charge carrier transport behavior of PDSGTPD was investigated via electrical field-effect measurements using bottom-gate, top-contact transistor architectures made on doped heavily doped $\mathrm{Si}^{++}$wafers as the gate electrode and a 400 nm-thick thermally oxidized silicon dioxide as the gate dielectric layer. The dielectric was treated with HMDS or OTS prior to deposition of the semiconductor, with the best results obtained for OTS treated $\mathrm{SiO}_{2}$ based transistors. The devices exhibit typical p-type behavior, with typical transfer and output characteristics shown in Fig. 3. The polymers exhibited average as cast saturated and linear mobilities of $8.4 \times 10^{-3} \mathrm{~cm}^{2} \mathrm{~V} \mathrm{~s}^{-1}$ and $2.6 \times 10^{-3} \mathrm{~cm}^{2} \mathrm{~V} \mathrm{~s}^{-1}$, respectively, with a peak saturated hole mobility of $\sim 1 \times 10^{-2} \mathrm{~cm}^{2} \mathrm{~V} \mathrm{~s}^{-1}$. The bottom-gate, top-contact performance of the analogous thiophene polymer has not been reported, but the transistor performance of the thiophene polymer with a silicon bridge rather than a germanium bridge has been reported in this device configuration. In that case, an average saturated mobility of $6 \times 10^{-4} \mathrm{~cm}^{2} \mathrm{~V} \mathrm{~s} \mathrm{~s}^{-1}$ was observed. ${ }^{22}$ The hole mobility observed for PDSGTPD in TFTs suggested that the polymer would have reasonable transport characteristics as a donor in $\mathrm{BHJ}$ solar cells.

The photovoltaic performance of PDSGTPD was investigated in devices using both conventional (ITO/PEDOT:PSS/ PDSGTPD: $\mathrm{PC}_{71} \mathrm{BM} / \mathrm{LiF} / \mathrm{Al}$ ) and inverted (ITO/ZnO/ PDSGTPD: $\mathrm{PC}_{71} \mathrm{BM} / \mathrm{MoO}_{3} / \mathrm{Ag}$ ) device structures and their power conversion efficiency was measured under $100 \mathrm{~mW} \mathrm{~cm}^{2} \mathrm{AM} 1.5$ illumination. Polymer:fullerene blends were solution processed from $o$-dichlorobenzene (ODCB), and due to the low band gap absorption of the polymer, $\mathrm{PC}_{71} \mathrm{BM}$ was used to complement and capture the low wavelength of the visible spectrum. ${ }^{23}$ The
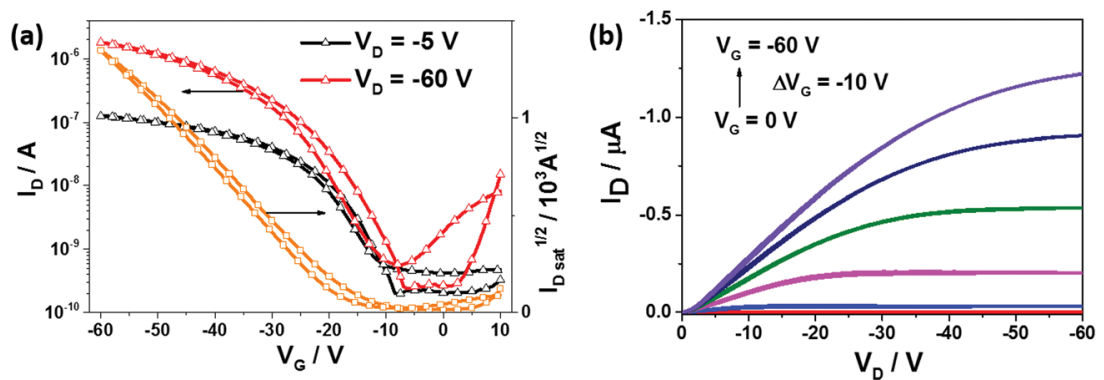

Fig. 3 Transfer (left) and output (right) characteristics of bottom gate, top contact organic field-effect transistor with channel length $=30 \mu \mathrm{m}$ and channel width $=1 \mathrm{~mm}$ under $\mathrm{N}_{2}$. 

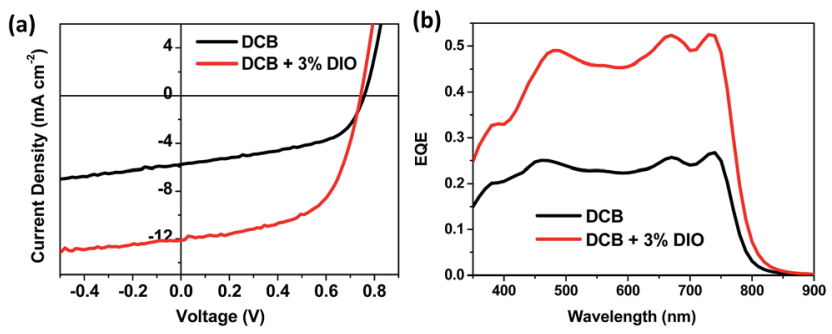

Fig. 4 (a) EQE corrected J-V curve and (b) EQE of inverted polymer solar cells based on PDSGTPD:PC ${ }_{71} \mathrm{BM}$ blends (1:2 wt $\%$ ) with or without solvent additives.

polymer was initially tested in a $1: 1,1: 2,1: 3$ and $1: 4$ weight ratio against $\mathrm{PC}_{71} \mathrm{BM}$ in the conventional device structure. Initial performance was rather poor, with the $1: 2$ blend giving the best efficiency around $1.5 \%$. The addition of 4 vol\% of $1,8-$ diiodooctane (DIO) as a processing additive ${ }^{24}$ resulted in a significant improvement in performance, with device efficiency improving to $4.6 \%$ (Fig. $55 \dagger$ ).

In an effort to further improve performance, inverted devices were also fabricated using the optimal $1: 2$ ratio. Fig. 4 shows the external quantum efficiency (EQE) corrected current density $v s$. voltage $(J-V)$ curves along with the actual EQE spectra, and the data is summarized in Table 1. Inverted devices showed improved efficiencies over the conventional architecture, both for films fabricated with and without DIO (Table 1). Slightly lower volumes of DIO gave the best performance in the inverted devices. The highest performing devices had an efficiency of $5.23 \%$, with reasonable $J_{\text {sc }}\left(12.2 \mathrm{~mA} \mathrm{~cm}^{-2}\right)$ and voltage $\left(V_{\mathrm{oc}}\right)$ but a moderate fill factor of 0.58 .

The external quantum efficiency (EQE) curves for the best devices are depicted in Fig. 4. Both devices show a broad spectral response in the $450-800 \mathrm{~nm}$ region, with EQE values doubled for devices with $3 \%$ DIO compared to the one without any additive. The EQE response in the 650-800 $\mathrm{nm}$ region closely resembles the absorption of the polymer spectrum, suggesting that significant photocurrent is generated from the polymer.

It is instructive to compare the performance of the PDSGTPD devices to that reported for the thiophene analogue (PDTGTPD) in blends with $\mathrm{PC}_{71} \mathrm{BM}$. Reynolds and so found that PDTGTPD exhibited the best performance in a $1: 1.5$ ratio with $\mathrm{PC}_{71} \mathrm{BM}$, in this instance for films cast from chlorobenzene (CB) with $5 \%$ vol of DIO. ${ }^{9 a, 25}$ They found a similar photocurrent $\left(12.6 \mathrm{~mA} \mathrm{~cm} \mathrm{~cm}^{-2}\right)$, but a significantly higher voltage $\left(V_{\mathrm{oc}} 0.85 \mathrm{~V}\right)$ and $\mathrm{FF}(0.68)$ leading to high efficiencies of 7.3\%. Two studies of PDTGTPD:PC ${ }_{71} \mathrm{BM} 1: 2 \mathrm{wt} \%$ blends processed from $\mathrm{CB} / \mathrm{DIO}$ in conventional device structure have also been reported. ${ }^{\mathbf{9 j , 2 6}}$ They both found slightly reduced performance, with photocurrents of 9.7 or $10.4 \mathrm{~mA} \mathrm{~cm} \mathrm{~cm}^{-2}$, voltages of 0.80 or $0.81 \mathrm{~V}$ and fill factors of 0.53 or 0.59 leading to overall efficiency of 4.1 or $4.9 \%$. It is difficult to fully determine the origin of the variation of the performance due to differences in processing conditions, film thicknesses and polymer molecular weights between the studies. Nevertheless in all three cases in it clear that PDTGTPD exhibits higher open circuit voltages than the selenophene polymer, in agreement with the DFT calculations, which suggest a slightly higher lying HOMO for the selenophene polymer. Similar reductions in voltage upon selenophene substitution have been previously reported. ${ }^{\mathbf{1 2 n , 1 2 y}}$ The photocurrent of PDSGTPD is also already close to the best reported for the thiophene polymer under highly optimised processing conditions, suggesting that the red shift of the absorption upon selenophene substitution can help improve photocurrent. Further improvements in the performance of PDSGTPD may be obtainable by further device optimisation.

In order to probe the role of the DIO, atomic force microscopy (AFM) was used to investigate the surface morphology of the blends of PDSGTPD : $\mathrm{PC}_{71} \mathrm{BM}(1: 2)$ with and without solvent additives, and their topography images are shown in Fig. 5. The AFM images show clear differences in the surface topography, with the DIO processed film exhibiting a much finer and more homogeneous distribution of feature sizes than the film without the additive. The surface roughness of the films with and without DIO are 2.69 and $4.55 \mathrm{~nm}$, respectively. The rather large domains and increased surface roughness in the absence of DIO are suggestive of poor intermixing between the fullerene and the polymer, which is generally considered non-optimal for good device performance.

In conclusion, we report the preparation of a novel diselenogermole (DSG) monomer and its polymerisation with 1,3dibromo-5-octyl-4H-thieno[3,4-c]pyrrole-4,6(5H)-dione by Stille polycondensation to afford a soluble low bad gap polymer. The polymer shows a broader and more red-shifted absorption spectrum compared to its thiophene analogue. The resulting polymer exhibits initial power conversion efficiencies of $5.2 \%$ in inverted bulk heterojunction solar cells, demonstrating that the DSG monomer is a promising building

Table 1 Summary of photovoltaic device performance of $1: 2$ ratio (PDSGTPD:PC ${ }_{71}$ BM) with or without additive. The average values of 6 devices values are shown, with the best performing device shown in parenthesis

\begin{tabular}{|c|c|c|c|c|}
\hline PDSGTPD:PC ${ }_{71} \mathrm{BM}(1: 2)$ & $J_{\mathrm{sc}}{ }^{a} \mathrm{~mA} \mathrm{~cm}{ }^{-2}$ & $V_{\mathrm{oc}}(\mathrm{V})$ & $\mathrm{FF}$ & PCE $(\%)$ \\
\hline DCB & $5.8 \pm 0.1(5.9)$ & $0.76 \pm 0.01(0.76)$ & $0.50 \pm 0.02(0.51)$ & $2.2 \pm 0.1(2.3)$ \\
\hline $\mathrm{DCB}+3 \% \mathrm{DIO}$ & $12.1 \pm 0.15(12.2)$ & $0.74 \pm 0.01(0.74)$ & $0.58 \pm 0.02(0.58)$ & $5.2 \pm 0.1(5.2)$ \\
\hline
\end{tabular}

${ }^{a} \mathrm{EQE}$ corrected. 


\section{(a) $\mathrm{RMS}=4.55 \mathrm{~nm}$}

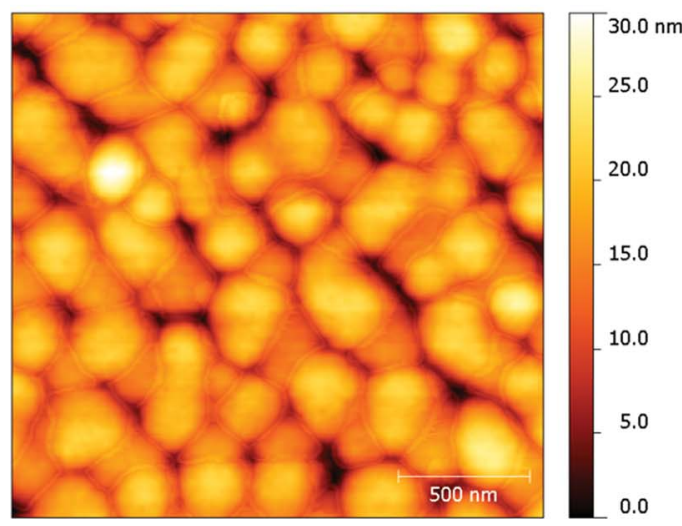

(b) $\mathrm{RMS}=2.69 \mathrm{~nm}$

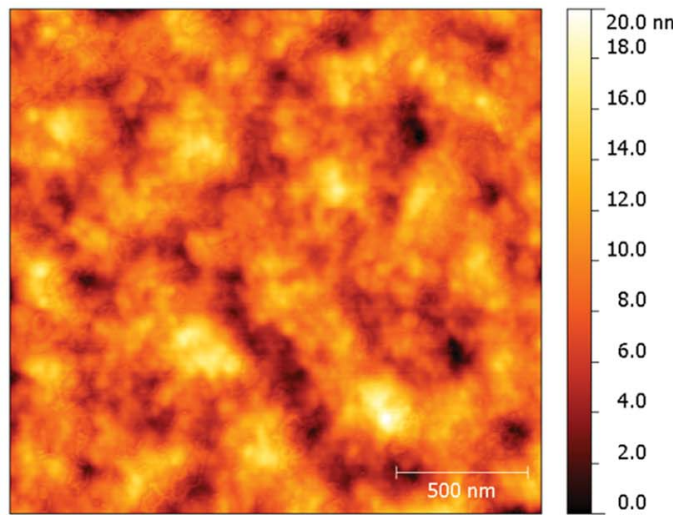

Fig. 5 AFM topography images $(2 \times 2 \mu \mathrm{m})$ based on PDSGTPD : PC ${ }_{71}$ BM blends $(1: 2$ wt\%) without (a) and with (b) solvent additives.

block for the design of new high performance conjugated polymers.

\section{Acknowledgements}

This work was supported by EPSRC grants EP/G060738/1 and EP/I002936/1, and NSF ICC Award CHE1026664.

\section{References}

1 (a) Y. He, W. Hong and Y. Li, J. Mater. Chem. C, 2014, 2, 8651; (b) K. Takimiya, I. Osaka and M. Nakano, Chem. Mater., 2014, 26, 587.

2 (a) I. McCulloch, R. S. Ashraf, L. Biniek, H. Bronstein, C. Combe, J. E. Donaghey, D. I. James, C. B. Nielsen, B. C. Schroeder and W. M. Zhang, Acc. Chem. Res., 2012, 45, 714; (b) C. L. Chochos and S. A. Choulis, Prog. Polym. Sci., 2011, 36, 1326; (c) X. Guo, M. Baumgarten and K. Müllen, Prog. Polym. Sci., 2013, 38, 1832; (d) P. Coppo and M. L. Turner, J. Mater. Chem., 2005, 15, 1123; (e) J. S. Wu, S. W. Cheng, Y. J. Cheng and C. S. Hsu, Chem. Soc. Rev., 2014, DOI: 10.1039/c4cs00250d.

3 P. Carbone and A. Troisi, J. Phys. Chem. Lett., 2014, 5, 2637. 4 N. E. Jackson, B. M. Savoie, K. L. Kohlstedt, M. Olvera de la Cruz, G. C. Schatz, L. X. Chen and M. A. Ratner, J. Am. Chem. Soc., 2013, 135, 10475.

5 H. N. Tsao, D. M. Cho, I. Park, M. R. Hansen, A. Mavrinskiy, D. Y. Yoon, R. Graf, W. Pisula, H. W. Spiess and K. Müllen, J. Am. Chem. Soc., 2011, 133, 2605.

6 D. Muehlbacher, M. Scharber, M. Morana, Z. Zhu, D. Waller, R. Guadiana and C. Brabec, Adv. Mater., 2006, 18, 2884.

7 G. L. Gibson and D. S. Seferos, Macromol. Chem. Phys., 2014, 215, 811.

8 (a) M. C. Scharber, M. Koppe, J. Gao, F. Cordella, M. A. Loi, P. Denk, M. Morana, H.-J. Egelhaaf, K. Forberich, G. Dennler, R. Gaudiana, D. Waller, Z. Zhu, X. Shi and C. J. Brabec, Adv. Mater., 2010, 22, 367; (b) H. Y. Chen, J. H. Hou, A. E. Hayden, H. Yang, K. N. Houk and Y. Yang, Adv. Mater., 2010, 22, 371; (c) J. S. Kim, Z. P. Fei,
D. T. James, M. Heeney and J. S. Kim, J. Mater. Chem., 2012, 22, 9975; (d) J. S. Kim, Z. Fei, S. Wood, D. T. James, M. Sim, K. Cho, M. J. Heeney and J. S. Kim, Adv. Energy Mater., 2014, 1400527.

9 (a) C. M. Amb, S. Chen, K. R. Graham, J. Subbiah, C. E. Small, F. So and J. R. Reynolds, J. Am. Chem. Soc., 2011, 133, 10062; (b) Z. Fei, J. S. Kim, J. Smith, E. B. Domingo, T. D. Anthopoulos, N. Stingelin, S. E. Watkins, J.-S. Kim and M. Heeney, J. Mater. Chem., 2011, 21, 16257; (c) Y.-M. Hwang, J. Ohshita, Y. Harima, T. Mizumo, Y. Ooyama, Y. Morihara, T. Izawa, T. Sugioka and A. Fujita, Polymer, 2011, 52, 3912; (d) X. Guo, N. Zhou, S. J. Lou, J. W. Hennek, R. Ponce Ortiz, M. R. Butler, P.-L. T. Boudreault, J. Strzalka, P.-O. Morin, M. Leclerc, J. T. Lopez Navarrete, M. A. Ratner, L. X. Chen, R. P. H. Chang, A. Facchetti and T. J. Marks, J. Am. Chem. Soc., 2012, 134, 18427; (e) Z. P. Fei, Y. Kim, J. Smith, E. B. Domingo, N. Stingelin, M. A. McLachlan, K. Song, T. D. Anthopoulos and M. Heeney, Macromolecules, 2012, 45, 735; $(f)$ Z. P. Fei, M. Shahid, N. Yaacobi-Gross, S. Rossbauer, H. L. Zhong, S. E. Watkins, T. D. Anthopoulos and M. Heeney, Chem. Commun., 2012, 48, 11130; (g) Q. Wang, S. Zhang, L. Ye, Y. Cui, H. Fan and J. Hou, Macromolecules, 2014, 47, 5558; (h) C. P. Yau, Z. Fei, R. S. Ashraf, M. Shahid, S. E. Watkins, P. Pattanasattayavong, T. D. Anthopoulos, V. G. Gregoriou, C. L. Chochos and M. Heeney, Adv. Funct. Mater., 2014, 24, 678; (i) F.-B. Zhang, J. Ohshita, M. Miyazaki, D. Tanaka and Y. Morihara, Polym. J., 2014, 46, 628; (j) D. Gendron, P.-O. Morin, P. Berrouard, N. Allard, B. R. Aich, C. N. Garon, Y. Tao and M. Leclerc, Macromolecules, 2011, 44, 7188; ( $k$ ) J. Ohshita, M. Nodono, T. Watanabe, Y. Ueno, A. Kunai, Y. Harima, K. Yamashita and M. Ishikawa, J. Organomet. Chem., 1998, 553, 487; (l) H. Usta, G. Lu, A. Facchetti and T. J. Marks, J. Am. Chem. Soc., 2006, 128, 9034; $(m)$ J. W. Chen and Y. Cao, Macromol. Rapid Commun., 2007, 28, 1714; (n) L. Liao, L. Dai, A. Smith, M. Durstock, J. Lu, J. Ding and Y. Tao, Macromolecules, 
2007, 40, 9406; (o) P. M. Beaujuge, W. Pisula, H. N. Tsao, S. Ellinger, K. Muellen and J. R. Reynolds, J. Am. Chem. Soc., 2009, 131, 7514; (p) J. Ding, N. Song and Z. Li, Chem. Commun., 2010, 46, 8668; (q) C. Cui, X. Fan, M. Zhang, J. Zhang, J. Min and Y. Li, Chem. Commun., 2011, 47, 11345; (r) P. M. Beaujuge, H. N. Tsao, M. R. Hansen, C. M. Amb, C. Risko, J. Subbiah, K. R. Choudhury, A. Mavrinskiy, W. Pisula, J.-L. Bredas, F. So, K. Muellen and J. R. Reynods, J. Am. Chem. Soc., 2012, 134, 8944; (s) T.-Y. Chu, J. Lu, S. Beaupre, Y. Zhang, J.-R. Pouliot, J. Zhou, A. Najari, M. Leclerc and Y. Tao, Adv. Funct. Mater., 2012, 22, 2345; $(t)$ X. Guo, N. Zhou, S. J. Lou, J. W. Hennek, R. Ponce Ortiz, M. R. Butler, P.-L. T. Boudreault, J. Strzalka, P.-O. Morin, M. Leclerc, J. T. López Navarrete, M. A. Ratner, L. X. Chen, R. P. H. Chang, A. Facchetti and T. J. Marks, J. Am. Chem. Soc., 2012, 134, 18427; (u) J. Min, Z.-G. Zhang, M. Zhang and Y. Li, Polym. Chem., 2013, 4, 1467. 10 A. Patra and M. Bendikov, J. Mater. Chem., 2010, 20, 422.

11 S. S. Zade, N. Zamoshchik and M. Bendikov, Chem.-Eur. J., 2009, 15, 8613.

12 (a) M. Heeney, W. Zhang, D. J. Crouch, M. L. Chabinyc, S. Gordeyev, R. Hamilton, S. J. Higgins, I. McCulloch, P. J. Skabara, D. Sparrowe and S. Tierney, Chem. Commun., 2007, 5061; (b) M. Al-Hashimi, M. A. Baklar, F. Colleaux, S. E. Watkins, T. D. Anthopoulos, N. Stingelin and M. Heeney, Macromolecules, 2011, 44, 5194; (c) J. Hollinger, D. Gao and D. S. Seferos, Isr. J. Chem., 2014, 54, 440; (d) A. Patra, R. Kumar and S. Chand, Isr. J. Chem., 2014, 54, 621; (e) A. A. B. Alghamdi, D. C. Watter, H. Yi, S. Al-Faifi, M. S. Almeataq, D. Coles, J. Kingsley, D. G. Lidzey and A. Iraqi, J. Mater. Chem. A, 2013, 1, 5165; (f) D. Gao, J. Hollinger, A. A. Jahnke and D. S. Seferos, J. Mater. Chem. A, 2014, 2, 6058; $(g)$ H. Yan, J. Hollinger, C. R. Bridges, G. R. McKeown, T. Al-Faouri and D. S. Seferos, Chem. Mater., 2014, 26, 4605; (h) A. Bedi, S. P. Senanayak, K. S. Narayan and S. S. Zade, Macromolecules, 2013, 46, 5943; (i) H. Kong, Y. K. Jung, N. S. Cho, I.-N. Kang, J.-H. Park, S. Cho and H.-K. Shim, Chem. Mater., 2009, 21, 2650; (j) Z. Y. Chen, H. Lemke, S. Albert-Seifried, M. Caironi, M. M. Nielsen, M. Heeney, W. M. Zhang, I. McCulloch and H. Sirringhaus, Adv. Mater., 2010, 22, 2371; (k) J. S. Ha, K. H. Kim and D. H. Choi, J. Am. Chem. Soc., 2011, 133, 10364; (l) W.-H. Lee, S. K. Son, K. Kim, S. K. Lee, W. S. Shin, S.-J. Moon and I.-N. Kang, Macromolecules, 2012, 45, 1303; $(m)$ H. A. Saadeh, L. Lu, F. He, J. E. Bullock, W. Wang, B. Carsten and L. Yu, ACS Macro Lett., 2012, 1, 361; (n) M. Shahid, R. S. Ashraf, Z. Huang, A. J. Kronemeijer, T. McCarthy-Ward, I. McCulloch, J. R. Durrant, H. Sirringhaus and M. Heeney, J. Mater. Chem., 2012, 22, 12817; (o) C.-C. Chang, C.-P. Chen, H.-H. Chou, C.-Y. Liao, S.-H. Chan and C.-H. Cheng, J. Polym. Sci., Part A-1: Polym. Chem., 2013, 51, 4550; (p) T. Earmme, Y.-J. Hwang, N. M. Murari, S. Subramaniyan and S. A. Jenekhe, J. Am. Chem. Soc., 2013, 135, 14960; (q) I. Kang, T. K. An, J.-a. Hong, H.-J. Yun, R. Kim, D. S. Chung, C. E. Park, Y.-H. Kim and S.-K. Kwon, Adv. Mater., 2013, 25, 524; (r) A. E. Rudenko,
S. Noh and B. C. Thompson, Nanotechnology, 2013, 24, 484002; (s) J. Cao, S. Chen, Z. Qi, Z. Xiao, J. Wang and L. Ding, $R S C A d v$., 2014, 4, 5085; ( $t$ ) J.-H. Kim, J. B. Park, S. A. Shin, M. H. Hyun and D.-H. Hwang, Polymer, 2014, 55, 3605; $(u)$ R. L. Uy, L. Yan, W. Li and W. You, Macromolecules, 2014, 47, 2289; (v) A. M. Ballantyne, L. C. Chen, J. Nelson, D. D. C. Bradley, Y. Astuti, A. Maurano, C. G. Shuttle, J. R. Durrant, M. Heeney, W. Duffy and I. McCulloch, Adv. Mater., 2007, 19, 4544; (w) M. Shahid, T. McCarthy-Ward, J. Labram, S. Rossbauer, E. B. Domingo, S. E. Watkins, N. Stingelin, T. D. Anthopoulos and M. Heeney, Chem. Sci., 2012, 3, 181; (x) J. H. Bannock, M. Al-Hashimi, S. H. Krishnadasan, J. J. M. Halls, M. Heeney and J. C. de Mello, Mater. Horiz., 2014, 1, 214; (y) K. H. Hendriks, W. Li, M. M. Wienk and R. A. J. Janssen, J. Am. Chem. Soc., 2014, 136, 12130; (z) H.-Y. Chen, S.-C. Yeh, C.-T. Chen and C.-T. Chen, J. Mater. Chem., 2012, 22, 21549; (aa) K. A. Mazzio, M. Yuan, K. Okamoto and C. K. Luscombe, ACS Appl. Mater. Interfaces, 2011, 3, 271; (ab) Z. Zeng, Y. Li, J. Deng, Q. Huang and Q. Peng, J. Mater. Chem. A, 2014, 2, 653; (ac) L. Dou, W.-H. Chang, J. Gao, C.-C. Chen, J. You and Y. Yang, Adv. Mater., 2013, 25, 825; (ad) J. Warnan, A. El Labban, C. Cabanetos, E. T. Hoke, P. K. Shukla, C. Risko, J.-L. Brédas, M. D. McGehee and P. M. Beaujuge, Chem. Mater., 2014, 26, 2299.

13 (a) Y. A. Getmanenko, T. A. Purcell, D. K. Hwang, B. Kippelen and S. R. Marder, J. Org. Chem., 2012, 77, 10931; (b) Y. A. Getmanenko, P. Tongwa, T. V. Timofeeva and S. R. Marder, Org. Lett., 2010, 12, 2136.

14 (a) Y. A. Getmanenko, C. Risko, P. Tongwa, E.-G. Kim, H. Li, B. Sandhu, T. Timofeeva, J.-L. Brédas and S. R. Marder, J. Org. Chem., 2011, 76, 2660; (b) S. Tarutani and K. Takahashi, Bull. Chem. Soc. Jpn., 2004, 77, 463.

15 S. V. Kesava, Z. Fei, A. D. Rimshaw, C. Wang, A. Hexemer, J. B. Asbury, M. Heeney and E. D. Gomez, Adv. Energy Mater., 2014, 4, 1400116.

16 H. S. Chandak and S. S. Zade, Org. Electron., 2014, 15, 2184. 17 (a) C. Piliego, T. W. Holcombe, J. D. Douglas, C. H. Woo, P. M. Beaujuge and J. M. J. Fréchet, J. Am. Chem. Soc., 2010, 132, 7595; (b) J. Warnan, C. Cabanetos, A. E. Labban, M. R. Hansen, C. Tassone, M. F. Toney and P. M. Beaujuge, Adv. Mater., 2014, 26, 4357; (c) H. L. Zhong, Z. Li, F. Deledalle, E. C. Fregoso, M. Shahid, Z. P. Fei, C. B. Nielsen, N. Yaacobi-Gross, S. Rossbauer, T. D. Anthopoulos, J. R. Durrant and M. Heeney, J. Am. Chem. Soc., 2013, 135, 2040; (d) D. H. Wang, A. Pron, M. Leclerc and A. J. Heeger, Adv. Funct. Mater., 2013, 23, 1297.

18 C. B. Nielsen and T. Bjørnholm, Org. Lett., 2004, 6, 3381. 19 S. Gronowitz and T. Frejd, Acta Chem. Scand., 1970, 24, 2656. 20 S. Tierney, M. Heeney and I. McCulloch, Synth. Met., 2005, 148, 195.

21 C. P. Yau, S. Wang, N. D. Treat, B. J. Tremolet de Villers, M. L. Chabinyc and M. Heeney, Adv. Energy Mater., 2014, 1401228. 
22 Y. Zhang, J. Zou, H.-L. Yip, Y. Sun, J. A. Davies, K.-S. Chen, O. Acton and A. K. Y. Jen, J. Mater. Chem., 2011, 21, 3895.

23 M. M. Wienk, J. M. Kroon, W. J. H. Verhees, J. Knol, J. C. Hummelen, P. A. van Hal and R. A. J. Janssen, Angew. Chem., Int. Ed., 2003, 42, 3371.

24 J. K. Lee, W. L. Ma, C. J. Brabec, J. Yuen, J. S. Moon, J. Y. Kim, K. Lee, G. C. Bazan and A. J. Heeger, J. Am. Chem. Soc., 2008, 130, 3619.
25 C. E. Small, S. Chen, J. Subbiah, C. M. Amb, S.-W. Tsang, T.-H. Lai, J. R. Reynolds and F. So, Nat. Photonics, 2012, 6, 115.

26 Y. Zhang, J. Zou, H.-L. Yip, Y. Sun, J. A. Davies, K.-S. Chen, O. Acton and A. K. Y. Jen, J. Mater. Chem., 2011, 21, 3895. 